\title{
Archival report
}

\section{Acute effects of LSD in healthy subjects}

Yasmin Schmid, Florian Enzler, Peter Gasser, Eric Grouzmann, Katrin H. Preller, Franz X. Vollenweider, Rudolf Brenneisen, Felix Müller, Stefan Borgwardt, Matthias E. Liechti

From Psychopharmacology Research, Clinical Pharmacology and Toxicology, Department of Biomedicine and Department of Clinical Research, University Hospital Basel, Switzerland (YS, FE, MEL), Practice for Psychiatry and Psychotherapy, Solothurn, Switzerland (PG), Biomedicine Service, University Hospital Lausanne, Lausanne, Switzerland (EG) Neuropsychopharmacology and Brain Imaging and Heffter Research Center, Department of Psychiatry, Psychotherapy and Psychosomatics, University Hospital of Psychiatry Zurich, Switzerland (KHP, FXV), Department of Clinical Research, University of Bern, Bern, Switzerland (RB), and Department of Psychiatry, University of Basel, Basel, Switzerland (FM, SB).

Short title: Effects of LSD

Address correspondence to Prof. Matthias E. Liechti, MD, Clinical Pharmacology, University Hospital Basel, Hebelstrasse 2, Basel, CH-4031, Switzerland; E-mail: matthias.liechti@usb.ch; Phone: +4161328 68 68; Fax: +4161265 4560

Word counts: Abstract: 250; Manuscript: 3940

References: 90

Tables and Figures: Tables: 0; Figures: 6

Supplemental material online: 1 file with 3 tables and 4 figures

Keywords: LSD, prepulse inhibition, subjective effects, hormones, adverse effects, sympathomimetic effects 


\section{Summary}

Background: After no research in humans for more than 40 years, there is renewed interest in using lysergic acid diethylamide (LSD) in clinical psychiatric research and practice. There are no modern studies on the subjective and autonomic effects of LSD and its endocrine effects are unknown. LSD disrupts prepulse inhibition (PPI) of the acoustic startle response in animals, and schizophrenia patients exhibit similar impairments in PPI. However, no data are available on the effects of LSD on PPI in humans.

Methods: LSD $(200 \mu \mathrm{g})$ and placebo were administered to 16 healthy subjects (eight women, eight men) in a double-blind, randomized, placebo-controlled, cross-over study. The outcome measures included psychometric scales, investigator ratings, PPI of the acoustic startle response, autonomic, endocrine, and adverse effects.

Results: LSD produced pronounced alterations in waking consciousness that lasted $12 \mathrm{~h}$. LSD predominantly induced visual hallucinations, audio-visual synesthesia, and positively experienced derealization and depersonalization phenomena. LSD also increased subjective well-being, happiness, closeness to others, openness, and trust. LSD decreased PPI compared with placebo. LSD significantly increased blood pressure, heart rate, body temperature, pupil size, plasma cortisol, prolactin, oxytocin, and epinephrine. LSD produced adverse effects which completely subsided within $72 \mathrm{~h}$. No severe acute adverse effects were observed.

Conclusions: In addition to marked hallucinogenic effects, LSD exerts MDMA-like empathogenic mood effects that may be useful in psychotherapy. LSD altered sensorimotor gating in a human model of psychosis, supporting the use of LSD in translational psychiatric research. LSD can safely be used in a controlled clinical setting but produces significant sympathomimetic stimulation.

Trial registration: clinicaltrials.gov Identifier: NCT01878942 


\section{Introduction}

Lysergic acid diethylamide (LSD) is a prototypical classic hallucinogen $(1,2)$. The psychotropic effects of LSD were discovered in 1943 by Albert Hofmann in Basel (3). In the 1950s to 1970s, LSD was initially used as an experimental tool ("psychotomimetic") to study psychotic-like states and model psychosis $(4,5)$ and as an adjunct in "psycholytic psychotherapy." LSD has also been investigated for the treatment of alcoholism (6), addiction (7), cluster headache (8), and anxiety associated with terminal illness (9-11). Today, LSD is illicitly used for recreational (personal or spiritual) purposes. The lifetime prevalence of LSD use among adults is in the range of $6-8 \%(12,13)$. Despite LSD's widespread recreational use, no scientific pharmacological studies have been conducted with LSD in the last 40 years. After the initial psychiatric investigation by Stoll (14), several case reports and studies in the 1950s and 1960s described aspects of the psychological effects of LSD $(5,15-17)$. However, these studies were not performed according to today's research standards and did not include control conditions or the systematic characterization of psychotropic effects. Many studies also sought to describe the psychotomimetic effects of LSD but were not designed to measure any positive subjective effects. Modern experimental studies with hallucinogens in humans resumed in the 1990s with $N$-N-dimethyltryptamine (DMT, ayahuasca) (18-21), ketamine (2123), and psilocybin $(24,25)$ but not with LSD. Both LSD and psilocybin have also been recently evaluated in pilot therapeutic studies as treatments for anxiety in patients with lifethreatening diseases $(11,26)$. Because of the continued popularity of LSD as a recreational drug and renewed interest in its therapeutic use $(11,27)$, we reexamined the acute response to LSD in healthy subjects. To allow for a better characterization of the subjective effects of LSD, we used psychometric instruments that have been used with other psychotropic drugs, including hallucinogens, empathogens, and stimulants $(20,21,28-31)$.

Serotonergic hallucinogens, including psilocybin, DMT, and LSD, elicit mostly visual perceptual disturbances that are partially similar to those observed in early schizophrenia (21, 32-34). Hallucinogens also induce alterations in information processing that are similar to those observed in schizophrenia. Specifically, prepulse inhibition (PPI) of the acoustic startle 
response serves as an operational measure of sensorimotor gating that can be assessed in animals and humans (35). PPI is impaired in schizophrenia and also in prodromal states and early phases (35-38), and hallucinogens like LSD acutely disrupt PPI in animals (39-44). Prepulse inhibition in animals, therefore, serves as a preclinical model of schizophrenia (45). However, the effects of LSD on sensorimotor gating function have not yet been explored in humans and therefore were tested in the present study. We hypothesized that LSD would produce alterations in waking consciousness and impair PPI. Additionally, no data are available on the acute autonomic and adverse effects of LSD and the endocrine effects of LSD in humans are unknown. Thus, up-to-date clinical safety data are mostly missing. Because of the continued popularity of LSD as a recreational drug and interest in its therapeutic use, we also examined the acute somatic and endocrine response to LSD.

\section{Material and Methods}

\section{Participants}

Sixteen healthy subjects (eight men and eight women; mean age $\pm S D$ : $28.6 \pm 6.2$ years; range: 25-51 years) were recruited by word of mouth or an advertisement placed on the web market platform of the University of Basel. All of the subjects provided written informed consent and were paid for their participation. Additionally, we considered the safety recommendations for high-dose hallucinogen research $(46,47)$. The participant characteristics are described in detail in Supplement 1. Seven subjects had used a hallucinogen 1-3 times and another four subjects had prior experience with MDMA (2-4 times).

\section{Study design}

The study used a double-blind, placebo-controlled, cross-over design with two experimental test sessions in balanced order. The washout periods between sessions were at least 7 days. The study was conducted in accordance with the Declaration of Helsinki and International Conference on Harmonization Guidelines in Good Clinical Practice (ICH-GCP) 
and approved by the Ethics Committee of the Canton of Basel, Switzerland, and Swiss Agency for Therapeutic Products (Swissmedic). The administration of LSD to healthy subjects was authorized by the Swiss Federal Office for Public Health, Bern, Switzerland. The study was registered at ClinicalTrials.gov (NCT01878942).

\section{Drugs}

LSD was administered in a single absolute dose of $200 \mu \mathrm{g}$, corresponding to a dose of $2.84 \pm 0.13 \mu \mathrm{g} / \mathrm{kg}$ body weight (mean $\pm S E M$; range, 2.04-3.85 $\mu \mathrm{g}$ ). The same dose was used in LSD-assisted psychotherapy in a clinical study (11). The dose was within the range of doses taken for recreational purposes and expected to induce robust effects in humans (1). The drug preparation is described in Supplement 1.

\section{Study procedures}

The study included a screening visit with the study physician, a separate psychiatric interview, an additional visit with the study physician for familiarization, two $25 \mathrm{~h}$ test sessions, and an end-of-study visit. The sessions were conducted in a calm laboratory environment. Only one research subject and one or two investigators were present during the test sessions. The test sessions began at 8:15 AM. A urine sample was taken to verify abstinence from drugs of abuse, and a urine pregnancy test was performed in women. The subjects then underwent baseline measurements. LSD $(200 \mu \mathrm{g})$ or placebo was administered at 9:00 AM. The outcome measures were repeatedly assessed for $24 \mathrm{~h}$. A standardized lunch and dinner was served at 1:30 PM and 5:30 PM, respectively. The subjects were under constant supervision by the study physician until 1:00 AM. Thus, the subjects were never alone during the first $16 \mathrm{~h}$ after drug administration, and the investigator was in a room next to the subject for up to $24 \mathrm{~h}$. The subjects were sent home the next day at 9:30 AM.

\section{Subjective drug effects}


Subjective measures included scores on the 5 Dimensions of Altered States of Consciousness (5D-ASC) scale $(28,48)$, Visual Analogue Scales (VASs) (49), the Adjective Mood Rating Scale (AMRS) (50), and the Addiction Research Center Inventory (ARCI) (30). The 5D-ASC scale is designed to be used retrospectively and was administered $24 \mathrm{~h}$ after drug administration to rate the peak drug effects. The VASs were administered repeatedly up to $24 \mathrm{~h}$ to assess drug effects over time. The AMRS and ARCI were administered before and 3, 10, and $24 \mathrm{~h}$ after drug administration. The procedures are described in detail in Supplement 1.

\section{Acoustic startle response measurement}

The eye-blink component of the acoustic startle response was measured using an electromyographic startle system (EMG-SR-Lab; San Diego Instruments, San Diego, CA, USA) as described in detail elsewhere (35) and in Supplement 1. Briefly, the session included 16 pulse-alone stimuli $(115 \mathrm{~dB})$ and 32 similar pulse trials that were preceded by a $20 \mathrm{~ms}$ prepulse $(86 \mathrm{~dB})$ and an interstimulus interval (ISI) of $30,60,120$, or $2000 \mathrm{~ms}$, resulting in four prepulse trial conditions.

Cardiovascular, autonomic, adverse, and endocrine effects

Cardiostimulant (blood pressure, heart rate), autonomic (body temperature, pupillary function), psychomotor performance, endocrine measures (plasma cortisol, prolactin, oxytocin, norepinephrine, and epinephrine), and adverse effects were measured as described in Supplement 1.

\section{Data analysis}

The data were analyzed using Statistica 12 software (StatSoft, Tulsa, OK, USA). Peak $\left(E_{\max }\right)$ or peak change from baseline $\left(\Delta \mathrm{E}_{\max }\right)$ values were determined for repeated measures. Data were then analyzed using repeated-measures analysis of variance (ANOVA), with drug (LSD vs. placebo) as the within-subjects factor. The PPI data were analyzed using repeated- 
measures ANOVA, with drug and trial condition $(30,60,120$, and $2000 \mathrm{~ms})$ as within-subjects factors, followed by direct comparisons for each trial condition. Modulatory effects of sex and hallucinogen experience were evaluated by including the respective between-subjects factor into the ANOVA. Spearman's rank correlations were used to determine associations between measures. The criterion for statistical significance was $p<.05$.

\section{Results}

Subjective drug effects

Altered states of consciousness on the 5D-ASC. LSD induced pronounced alterations of waking consciousness (Fig. 1). LSD most strongly increased ratings of oceanic boundlessness $\left(F_{1,15}=92.3, p<.001\right)$ and visionary restructuralization $\left(F_{1,15}=243.5, p<.001\right)$. The elevated ratings for oceanic boundlessness indicated that LSD elicited a state of positively experienced derealization and depersonalization with predominantly increased ratings for "experience of unity" $\left(F_{1,15}=60.2, p<.001\right)$ and "blissful state" $\left(F_{1,15}=68.1, p<.001\right)$. Additionally, LSD produced marked visionary restructuralization phenomena, including increased ratings for "elementary and complex imagery" $\left(F_{1,15}=123.8, p<.001\right.$, and $F_{1,15}=55.9, p<.001$, respectively), "audio-visual synesthesia" $\left(F_{1,15}=156.8, \quad p<.001\right)$, and "changed meaning of percepts" $\left(F_{1,15}=93.3, p<.001\right)$. LSD induced only minimal "auditory alterations" $\left(F_{1,15}=34.5, p<.001\right)$. LSD also moderately increased ratings of anxious ego-dissolution $\left(F_{1,15}=16.1, p<.01\right)$, mostly attributable to significantly increased ratings for "disembodiment" $\left(F_{1,15}=34.4, p<.001\right)$ and "impaired control and cognition" $\left(F_{1,15}=25.3, p<.001\right)$, but not "anxiety" $\left(F_{1,15}=4.2, p=.06\right)$. Profound anxiety or panic was not experienced by any subject. However, two subjects (one female and one male) reacted with transient anxiety, including fear of losing control, which completely resolved without pharmacological intervention within 2-3h. No sex differences were observed in the effects of LSD on the 5D-ASC scale.

Psychotropic effects over time on VASs. Subjective effects on the VASs are shown in Fig. 2, and maximal effects are presented in supplementary Table S2. The subjective effects began 30-60min after LSD administration. Peak effects (any drug effects) were reported after 
(mean $\pm S D) 1.75 \pm 0.82 \mathrm{~h}$. After $5 \mathrm{~h}$, the subjective effects of LSD gradually subsided but lasted up to $12 \mathrm{~h}$ after LSD administration. Three subjects still rated the subjective effects $>50 \%$ of maximal possible effects at $12 \mathrm{~h}$. LSD produced pronounced increases in all VAS ratings, including "any drug effects," "good drug effect," "drug high," "drug liking," and "stimulated," compared with placebo (all $F_{1,15} \geq 1931$, all $p<.001$ ). Peak effects for "any drug effects," "good drug effect," and "drug liking" reached up to $90 \%$ of the maximal possible score. Additionally, LSD significantly increased ratings of "empathogenic" drug effects, including "happy," "closeness," "open", and "trust" (all $F_{1,15} \geq 34$, all p<.001). LSD decreased subjective concentration $\left(F_{1,15}=212.5, p<.001\right)$. LSD induced small but significant increases in "bad drug effect" and "fear" $\left(F_{1,15}=23.9, p<.001\right.$, and $F_{1,15}=13.2, p=.003$, respectively $)$ compared with placebo. The subjective effects of LSD did not differ between sexes.

$\underline{\text { AMRS. }}$ LSD significantly increased ratings of "well-being" $\left(F_{1,15}=8.2, p<.05\right)$, "emotional excitation" $\left(F_{1,15}=17.4, p<.001\right)$, "inactivity" $\left(F_{1,15}=10.8, p<.01\right)$, "introversion" $\left(F_{1,15}=16.9\right.$, $p<.001)$, and "dreaminess" $\left(F_{1,15}=57.9, p<.001\right)$ compared with placebo (Fig. 3, Table S2). LSD did not alter ratings of "extroversion" or "anxiety." No sex differences were observed in the effects of LSD on the AMRS.

$\underline{\mathrm{ARCl}}$. Subjective effects on the ARCI are presented in Table S2 and Fig. S1. LSD significantly increased ratings on the amphetamine group scale $\left(F_{1,15}=15.8, p=.001\right)$, with a trend toward significantly reduced ratings on the benzedrine group scale $\left(F_{1,15}=3.8, p=.07\right)$. LSD also significantly increased ratings of euphoria and drug liking on the morphinebenzedrine group scale $\left(F_{1,15}=31.3, p<.001\right)$, sedation on the pentobarbital-alcohol group scale $\left(F_{1,15}=52.6, p<.001\right)$, and ratings on the LSD group scale $\left(F_{1,15}=24.4, p<.001\right)$, a measure of dysphoric and psychotomimetic changes. No sex differences were observed in the effects of LSD on the ARCI.

Investigator-rated drug effects. The investigator-rated drug effects are shown in Table S2 and Fig. S2. LSD increased investigator ratings of "any drug effect" $\left(F_{1,15}=449.7, p<.001\right)$, "distance from reality" $\left(F_{1,15}=21.7, p<.001\right)$, "happiness" $\left(F_{1,15}=37.4, p<.001\right)$, and "non-speech vocalization" $\left(F_{1,15}=6.9, p<.05\right)$. LSD did not significantly increase ratings for "anxiety" or 
"paranoid thinking." LSD did not alter the percentage of time "talking with the investigator" compared with placebo.

\section{Acoustic startle response}

The effects of LSD on PPI and startle response habituation are shown in Fig. 4. The data from one participant were excluded because of technical reasons. The two-way ANOVA, with drug and prepulse trial condition as within-subject factors, revealed a significant drug $\times$ prepulse trial interaction $\left(F_{3,42}=3.0, p<.05\right)$. LSD significantly reduced $\mathrm{PPI}$ in the $30 \mathrm{~ms}$ and $60 \mathrm{~ms}$ trial conditions $\left(F_{1,14}=5.5, p<.05\right.$, and $F_{1,14}=5.1, p<.05$, respectively $)$ and also tended to reduce $\mathrm{PPI}$ in the $120 \mathrm{~ms}$ trial condition $\left(F_{1,14}=3.4, p=.09\right.$; Fig. $\left.3 \mathrm{~A}\right)$. LSD nonsignificantly increased the startle response compared with placebo (mean reaction amplitude over all pulse-alone trials (mean $\pm S D$ ): $571 \pm 321$ units and $469 \pm 190$ units after administration of LSD and placebo, respectively. The two-way ANOVA for pulse-alone trials, with drug and block (time) as factors, showed a significant main effect of block, indicating habituation of the startle response over time $\left(F_{3,42}=12.8, p<.001\right)$. No drug $\times$ block interaction was observed, indicating similar habituation of the response over time in the LSD and placebo conditions (Fig. 4B). Similarly, LSD did not affect \%habituation compared with placebo. No associations were found between \%PPI disruption and any subjective effect ratings assessed shortly before or after the startle measurement.

Cardiovascular, autonomic, adverse, and endocrine effects

$E_{\max }$ values and statistics are shown in Table S2. LSD significantly increased systolic $\left(F_{1,15}=23.77, \quad p<.001\right)$ and diastolic blood pressure $\left(F_{1,15}=25.19, \quad p<.001\right)$, heart rate $\left(F_{1,15}=15.27, p=.001\right)$, and body temperature compared with placebo $\left(F_{1,15}=11.61, p=.004\right.$; Fig. 5). LSD significantly increased the pupil size in the dark and after a light stimulus $\left(F_{1,15}=22.71\right.$ and 36.33, respectively, both $p<.001$; Fig. S3). LSD significantly impaired the participants' ability to balance on one foot $\left(F_{1,15}=26.1, p=.001\right.$; Fig. S4). LSD significantly increased the plasma concentrations of cortisol $\left(F_{1,15}=198.03, \quad p<.001\right)$, prolactin $\left(F_{1,15}=10.13, \quad p<.01\right)$, 
oxytocin $\left(F_{1,15}=9.40, p<.01\right)$, and epinephrine $\left(F_{1,15}=8.95, p<.01 ;\right.$ Fig. 6$)$. LSD significantly increased the total acute $\left(0-10 \mathrm{~h} ; F_{1,15}=13.67, p<.01\right)$ and subacute $\left(10-24 \mathrm{~h} ; F_{1,15}=7.19, p<.05\right)$ adverse effects but not adverse effects at 24-72h compared with placebo. Adverse effects at 24-72h did not differ between LSD and placebo. The frequently reported acute adverse effects of LSD are presented in Table S3. There were no severe acute effects. The somatic and endocrine effects of LSD did not differ between sexes.

\section{Discussion}

\section{Subjective effects of $L S D$}

LSD induced a pronounced alteration in waking consciousness, including visual perceptual alterations, audio-visual synesthesia, and positively experienced derealization and depersonalization. LSD did not induce pronounced anxiety and overall produced high ratings of good drug effects and low ratings of bad drug effects. LSD also increased well-being, happiness, closeness to others, openness, and feelings of trust, effects typically associated with the empathogen MDMA (ecstasy) (51). The subjective effects of LSD began 30-60min after administration and peaked at $1.75 \mathrm{~h}$ but remained high for $3-5 \mathrm{~h}$ before gradually declining. The acute psychological effects of LSD lasted $12 \mathrm{~h}$ in most subjects and up to $16 \mathrm{~h}$ in some, which is longer than the $6-10$ or $12 \mathrm{~h}$ reported by others $(1,16,52)$. This could be attributable to the relatively high dose of LSD or more sensitive psychometric measures used in the present study. The LSD effects lasted twice as long as those of psilocybin $(6 \mathrm{~h})(53,54)$ and were longer than the effects of DMT $(<1 \mathrm{~h})(18)$ but possibly similarly long as those of mescaline $(17,55)$.

In the present study, LSD produced higher scores on the 5D-ASC scale compared with psilocybin in a similar population of healthy subjects (54). In particular, LSD produced $30 \%$ higher ratings for both oceanic boundlessness (mostly blissful state), $30 \%$ higher ratings for anxious ego dissolution, and $63 \%$ higher ratings for visionary restructuralization (mostly greater audio-visual synesthesia) compared with a high dose of psilocybin $(54,56)$. Compared 
with DMT and ketamine, LSD produced $50 \%$ higher ratings for both oceanic boundlessness, $50 \%$ higher ratings for visionary restructuralization, and comparably high ratings for anxious ego dissolution $(21,28)$. LSD produced similar ratings on the AMRS for emotional excitation, inactivation, and dreaminess compared with high-dose psilocybin (54). Similar to LSD, mean group anxiety scores were not appreciably increased by psilocybin (54). On the ARCI, LSD increased ratings on the amphetamine group scale and morphine-benzedrine group scale, suggesting stimulant and euphoric subjective effects that were similar to MDMA (57). In contrast, LSD reduced ratings on the benzedrine group scale, suggesting reduced energy and focus, unlike MDMA (57). LSD had overall similar effects to psilocybin on the ARCI (58). Interestingly, LSD increased subjective VAS ratings for happy, open, closeness to others, and trust. Similarly, the investigators rated subjects as being happier after administration of LSD compared with placebo. Similar subjective effects are typically produced by empathogens, such as MDMA, but not by stimulants $(29,59)$. Altogether, the psychometric findings indicate that LSD produced stronger perceptual alterations than the doses of other psychotropic drugs tested so far and also MDMA-like empathogenic mood effects. Additionally, LSD increased plasma oxytocin levels. Oxytocin is thought to contribute to the empathogenic and prosocial effects of MDMA (60) and may have similar effects in the case of LSD. Although LSD and MDMA were not compared in the same subjects, the present findings indicate that LSD exerts partially MDMA-like empathogenic effects that may be associated with common serotonergic and/or oxytocinergic properties (51). MDMA produces weak LSD-like perceptual alterations, likely via similar 5-hydroxytryptamine-2A (5- $\left.\mathrm{HT}_{2 \mathrm{~A}}\right)$ receptor stimulation (61). Pharmacologically, LSD acts as a direct partial agonist at serotonergic receptors $(2,62)$, whereas MDMA mostly acts as an indirect serotonergic agonist by releasing serotonin via the serotonin transporter (63).

The primary safety concerns with hallucinogen research are psychological rather than somatic adverse effects (1). In laboratory studies that use psilocybin, ketamine, or MDMA, moderate anticipatory anxiety is common at the beginning of the onset of the drug's effects $(58,64,65)$. Acute anxiety was also infrequently reported when LSD was administered at the 
same dose as the one used in the present study for LSD-assisted psychotherapy in patients with anxiety associated with life-threatening diseases (11). In the present study, LSD produced anxiety in two subjects, which resolved spontaneously with verbal support from the investigators. Anxiety was related to fear of loss of thought control, disembodiment, and loss of self as similarly described for psilocybin (54). Some subjects also had to be reminded of the transient state of the drug-induced experience. Importantly, all of the subjects had no current or past history of major psychiatric disorders and were well-informed about the setting, acquainted with and constantly supervised by the same investigator. Also of note, only half of the subjects in the present study were hallucinogen-naive and the other half had very limited prior experience with hallucinogenic drugs. We found no differences in the quality and extent of the response to LSD between the hallucinogen-naive and moderately experienced subjects. Consistent with this finding, prior experience with hallucinogenic drugs only moderately affected the response to psilocybin in a similar research setting (65).

\section{Sensorimotor gating of the acoustic startle response}

In line with our hypothesis, LSD disrupted PPI and therefore produced sensorimotor deficits similarly to those observed in schizophrenia (35-38). LSD (39-41) and other serotonergic hallucinogens (42-44) reduce PPI in animals. LSD also potentiated the startle magnitude and impaired habituation of the startle response in rats (66). Similar deficits in habituation were reported in schizophrenia patients $(35,37)$. Consistent with the preclinical findings, LSD reduced PPI in the present study at the $30-120 \mathrm{~ms}$ ISI. LSD did not significantly alter the startle response amplitude or its habituation. Psilocybin reduced PPI at a short ISI (30ms), had no effect at a medium ISI (60ms), and increased PPI at long ISIs (120-2000ms), without changing startle reactivity or habituation $(67,68)$. Thus, the effects of LSD and psilocybin on the acoustic startle response and its modulation were quite similar. Additionally, the disruption of PPI induced by psilocybin in humans at a short ISI (30ms) was prevented by administration of a $5-\mathrm{HT}_{2 \mathrm{~A}}$ receptor antagonist (69), consistent with similar preclinical studies of LSD (41). In contrast to the findings with LSD and psilocybin, DMT or ayahuasca had no 
effects on PPI, startle reactivity, or habituation in humans $(19,70)$. Altogether, the effects of LSD on PPI in normal humans were consistent with both the PPI deficits after LSD administration in animals and sensorimotor gating deficits in schizophrenia patients.

Serotonergic hallucinogens, including LSD, are hypothesized to act at the $5-\mathrm{HT}_{2 \mathrm{~A}}$ receptor $(2,53)$, which is upregulated in schizophrenia patients $(71)$. Prepulse inhibition is influenced by genetic variations in the $5-\mathrm{HT}_{2 \mathrm{~A}}$ receptor gene (72), and PPI deficits induced by psilocybin in humans depend on $5-\mathrm{HT}_{2 \mathrm{~A}}$ receptor stimulation (69). In animals, LSD disrupts PPI (39-41) also via 5- $\mathrm{HT}_{2 \mathrm{~A}}$ receptor stimulation (41). To further characterize the role of 5- $\mathrm{HT}_{2}$ receptors and other receptors in the subjective and sensorimotor psychotomimetic effects of LSD in humans, further studies should investigate the effects of receptor antagonists on the response to LSD using a similar experimental setting. The present findings lend support to the use of LSD to study the neurobiological basis of psychotic states in humans. To date, brain activation patterns have not yet been studied using LSD in neuroimaging studies, in contrast to several modern investigations that used psilocybin to model psychotic states $(24,25)$.

\section{Autonomic and endocrine effects}

LSD produced significant sympathomimetic effects including increases in blood pressure, heart rate, and pupil size. Similar findings were reported in early studies in the 1950s

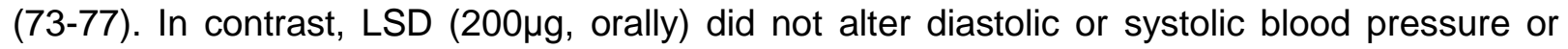
heart rate in a recent study in eight patients with different chronic life-threatening illnesses (11). Overall, the cardiostimulant effects of LSD were moderate and smaller than those seen with empathogens and stimulants (29). The LSD-induced increase in epinephrine levels in the present study was similar to the effect produced by MDMA (78).

LSD increased body temperature in the present study. LSD is thermogenic in animals (79) and hyperthermia has been reported to be a consequence of massive LSD overdose in humans (80). Other serotonergic hallucinogens including psilocybin and DMT produce similar cardiostimulant and autonomic responses to $\operatorname{LSD}(17,54,58,81-83)$. 
LSD increased circulating levels of cortisol and prolactin in the present study. LSD binds to dopaminergic $D_{2}$ receptors (84). LSD inhibited prolactin secretion by rat pituitary cells (85) and decreased plasma levels of prolactin in rats (86). This led to the suggestion that LSD acts as a dopamine $D_{2}$ receptor agonist in the pituitary. However, the present study in humans found that LSD increased the plasma levels of prolactin and cortisol, which are both markers of serotonergic activity $(87,88)$. Our findings suggest that the serotonergic stimulant effects of LSD on prolactin regulation usurp any dopamine $D_{2}$ receptor-mediated inhibition in humans at the dose used in the present study. Other serotonergic drugs, including psilocybin (54), DMT (83), ayahuasca (89), and MDMA $(29,90)$, increased the plasma levels of both prolactin and cortisol in humans.

The present study has several limitations. First, we only used a single dose of LSD, and we cannot provide dose-response data. We used a relatively high dose of LSD $(200 \mu \mathrm{g})$, which clearly produced a full and representative LSD response (1). The same dose of LSD was also recently used in patients with anxiety associated with terminal illness (11). Second, although we used formal blinding, the overt subjective effects of LSD unblinded the treatment assignment. Additionally, expectations may have influenced the psychological effects of LSD because all of the subjects knew that they would receive LSD or placebo and not another active drug. Furthermore, the psychological effects and risks of LSD are likely to be different from those described herein if LSD is used recreationally in unsupervised settings or in subjects with psychiatric disorders. Third, endocrine measures were performed only at two time-points during the expected peak drug effect, thus not allowing for a full characterization of the endocrine effects of LSD over a longer time interval.

In conclusion, LSD produced marked effects on perception but also subjective effects on mood that were similar to those reported for MDMA and increased plasma oxytocin, suggesting empathogenic properties that may be useful in psychotherapy (11). LSD acutely decreased PPI of the acoustic startle response, consistent with preclinical data and the 
sensorimotor deficits seen in schizophrenia. The present experimental human study may serve as an interface for the translation of preclinical research with hallucinogens to clinical research findings in patients with schizophrenia and vice versa. LSD may be useful for further studying alterations in consciousness and information processing in humans. The present study showed that LSD can be safely administered in an experimental research setting in humans, thus forming a basis for further psychopharmacological studies. However, the sympathomimetic stimulant effects need to be considered when LSD is to be used in patients with hypertension or heart disease.

\section{Acknowledgements}

This study was funded by the University Hospital Basel, Switzerland, and the Swiss National Science Foundation (grant no. 320030_1449493).

\section{Financial Disclosures}

The authors declare no conflict of interest.

Supplementary material cited in this article is available online. 


\section{References}

1. Passie T, Halpern JH, Stichtenoth DO, Emrich HM, Hintzen A (2008): The pharmacology of lysergic acid diethylamide: a review. CNS Neurosci Ther 14:295-314.

2. Nichols DE (2004): Hallucinogens. Pharmacol Ther 101:131-181.

3. Hofmann A (1979): How LSD originated. J Psychedelic Drugs 11:53-60.

4. Koelle GB (1958): The pharmacology of mescaline and D-lysergic acid diethylamide (LSD). N Engl J Med 258:25-32.

5. Bercel NA, Travis LE, Olinger LB, Dreikurs E (1956): Model psychoses induced by LSD-25 in normals. I. Psychophysiological investigations, with special reference to the mechanism of the paranoid reaction. AMA Arch Neurol Psychiatry 75:588-611.

6. Krebs TS, Johansen PO (2012): Lysergic acid diethylamide (LSD) for alcoholism: meta-analysis of randomized controlled trials. J Psychopharmacol 26:994-1002.

7. Savage C, McCabe OL (1973): Residential psychedelic (LSD) therapy for narcotic addict: a controlled study. Arch Gen Psychiatry 28:808-814.

8. Sewell RA, Halpern JH, Pope HG, Jr. (2006): Response of cluster headache to psilocybin and LSD. Neurology 66:1920-1922.

9. Grof S, Goodman LE, Richards WA, Kurland AA (1973): LSD-assisted psychotherapy in patients with terminal cancer. Int Pharmacopsychiatry 8:129-144.

10. Pahnke WN, Kurland AA, Goodman LE, Richards WA (1969): LSD-assisted psychotherapy with terminal cancer patients. Curr Psychiatr Ther 9:144-152.

11. Gasser P, Holstein D, Michel Y, Doblin R, Yazar-Klosinski B, Passie T, et al. (2014): Safety and efficacy of lysergic acid diethylamide-assisted psychotherapy for anxiety associated with life-threatening diseases. J Nerv Ment Dis 202:513-520.

12. EMCDDA (2014): European Drug Report 2014. European Monitoring Center for Drugs and Drug Addiction. www.emcdda.europa.eu. 
13. Johnston LD, O'Malley PM, Bachmann JG, Schulenberg JE, Miech RA (2014): Monitoring the Future: National Survey Results on Drug Use, 1975-2013: Volume 2, College Students and Adults Ages 19-55. Ann Arbor: Institute for Social Research, University of Michigan.

14. Stoll WA (1947): Lysergsäureäthylamid, ein Phantastikum aus der Mutterkorngruppe. Schweiz Arch Neurol Psychiatr 60:279-323.

15. Rothlin E (1957): Lysergic acid diethylamide and related substances. Ann N Y Acad Sci $66: 668-676$.

16. Salvatore S, Hyde RW (1956): Progression of effects of lysergic acid diethylamide (LSD). AMA Arch Neurol Psychiatry 76:50-59.

17. Hollister LE, Hartman AM (1962): Mescaline, lysergic acid diethylamide and psilocybin comparison of clinical syndromes, effects on color perception and biochemical measures. Compr Psychiatry 3:235-242.

18. Strassman RJ, Qualls CR, Uhlenhuth EH, Kellner R (1994): Dose-response study of $\mathrm{N}, \mathrm{N}$-dimethyltryptamine in humans. II. Subjective effects and preliminary results of a new rating scale. Arch Gen Psychiatry 51:98-108.

19. Riba J, Rodriguez-Fornells A, Barbanoj MJ (2002): Effects of ayahuasca on sensory and sensorimotor gating in humans as measured by P50 suppression and prepulse inhibition of the startle reflex, respectively. Psychopharmacology 165:18-28.

20. Dos Santos RG, Valle M, Bouso JC, Nomdedeu JF, Rodriguez-Espinosa J, Mcllhenny $\mathrm{EH}$, et al. (2011): Autonomic, neuroendocrine, and immunological effects of ayahuasca: a comparative study with d-amphetamine. J Clin Psychopharmacol 31:717726.

21. Gouzoulis-Mayfrank E, Heekeren K, Neukirch A, Stoll M, Stock C, Obradovic M, et al. (2005): Psychological effects of (S)-ketamine and N,N-dimethyltryptamine (DMT): a double-blind, cross-over study in healthy volunteers. Pharmacopsychiatry 38:301-311.

22. Krystal JH, Karper LP, Seibyl JP, Freeman GK, Delaney R, Bremner JD, et al. (1994): Subanesthetic effects of the noncompetitive NMDA antagonist, ketamine, in humans: 
psychotomimetic, perceptual, cognitive, and neuroendocrine responses. Arch Gen Psychiatry 51:199-214.

23. Vollenweider FX, Leenders KL, Scharfetter C, Antonini A, Maguire P, Missimer J, et al. (1997): Metabolic hyperfrontality and psychopathology in the ketamine model of psychosis using positron emission tomography (PET) and [18F]fluorodeoxyglucose (FDG). Eur Neuropsychopharmacol 7:9-24.

24. Carhart-Harris RL, Erritzoe D, Williams T, Stone JM, Reed LJ, Colasanti A, et al. (2012): Neural correlates of the psychedelic state as determined by fMRI studies with psilocybin. Proc Natl Acad Sci U S A 109:2138-2143.

25. Vollenweider FX, Leenders KL, Scharfetter C, Maguire P, Stadelmann O, Angst J (1997): Positron emission tomography and fluorodeoxyglucose studies of metabolic hyperfrontality and psychopathology in the psilocybin model of psychosis. Neuropsychopharmacology 16:357-372.

26. Grob CS, Danforth AL, Chopra GS, Hagerty M, McKay CR, Halberstadt AL, et al. (2011): Pilot study of psilocybin treatment for anxiety in patients with advanced-stage cancer. Arch Gen Psychiatry 68:71-78.

27. Kupferschmidt K (2014): High hopes. Science 345:18-23.

28. Studerus E, Gamma A, Vollenweider FX (2010): Psychometric evaluation of the altered states of consciousness rating scale (OAV). PLoS One 5:e12412.

29. Hysek CM, Simmler LD, Schillinger N, Meyer N, Schmid Y, Donzelli M, et al. (2014): Pharmacokinetic and pharmacodynamic effects of methylphenidate and MDMA administered alone and in combination. Int J Neuropsychopharmacol 17:371-381.

30. Martin WR, Sloan JW, Sapira JD, Jasinski DR (1971): Physiologic, subjective, and behavioral effects of amphetamine, methamphetamine, ephedrine, phenmetrazine, and methylphenidate in man. Clin Pharmacol Ther 12:245-258.

31. Hill HE, Haertzen CA, Wolbach AB Jr, Miner EJ (1963): The Addiction Research Center Inventory: standardization of scales which evaluate subjective effects of 
morphine, amphetamine, pentobarbital, alcohol, LSD-25, pyrahexyl and chlorpromazine. Psychopharmacologia 4:167-183.

32. Gouzoulis-Mayfrank E, Habermeyer E, Hermle L, Steinmeyer A, Kunert H, Sass H (1998): Hallucinogenic drug induced states resemble acute endogenous psychoses: results of an empirical study. Eur Psychiatry 13:399-406.

33. Geyer MA, Vollenweider FX (2008): Serotonin research: contributions to understanding psychoses. Trends Pharmacol Sci 29:445-453.

34. Langs RJ, Barr HL (1968): Lysergic acid diethylamide (LSD-25) and schizophrenic reactions: a comparative study. J Nerv Ment Dis 147:163-172.

35. Braff DL, Grillon C, Geyer MA (1992): Gating and habituation of the startle reflex in schizophrenic patients. Arch Gen Psychiatry 49:206-215.

36. Kumari V, Soni W, Mathew VM, Sharma T (2000): Prepulse inhibition of the startle response in men with schizophreni: effects of age of onset of illness, symptoms, and medication. Arch Gen Psychiatry 57:609-614.

37. Ludewig K, Geyer MA, Vollenweider FX (2003): Deficits in prepulse inhibition and habituation in never-medicated, first-episode schizophrenia. Biological Psychiatry $54: 121-128$.

38. Quednow BB, Frommann I, Berning J, Kuhn KU, Maier W, Wagner M (2008): Impaired sensorimotor gating of the acoustic startle response in the prodrome of schizophrenia. Biol Psychiatry 64:766-773.

39. Halberstadt AL, Geyer MA (2010): LSD but not lisuride disrupts prepulse inhibition in rats by activating the 5- $\mathrm{HT}_{2 \mathrm{~A}}$ receptor. Psychopharmacology (Berl) 208:179-189.

40. Palenicek T, Hlinak Z, Bubenikova-Valesova V, Novak T, Horacek J (2010): Sex differences in the effects of N,N-diethyllysergamide (LSD) on behavioural activity and prepulse inhibition. Prog Neuropsychopharmacol Biol Psychiatry 34:588-596.

41. Ouagazzal A, Grottick AJ, Moreau J, Higgins GA (2001): Effect of LSD on prepulse inhibition and spontaneous behavior in the rat: a pharmacological analysis and comparison between two rat strains. Neuropsychopharmacology 25:565-575. 
42. Sipes TE, Geyer MA (1997): DOI disrupts prepulse inhibition of startle in rats via 5$\mathrm{HT}_{2 \mathrm{~A}}$ receptors in the ventral pallidum. Brain Res 761:97-104.

43. Varty GB, Higgins GA (1995): Examination of drug-induced and isolation-induced disruptions of prepulse inhibition as models to screen antipsychotic drugs. Psychopharmacology (Berl) 122:15-26.

44. Krebs-Thomson K, Ruiz EM, Masten V, Buell M, Geyer MA (2006): The roles of 5-HT and $5-\mathrm{HT}_{2}$ receptors in the effects of 5-MeO-DMT on locomotor activity and prepulse inhibition in rats. Psychopharmacology (Berl) 189:319-329.

45. Halberstadt AL, Geyer MA (2013): Serotonergic hallucinogens as translational models relevant to schizophrenia. Int J Neuropsychopharmacol 16:2165-2180.

46. Johnson M, Richards W, Griffiths R (2008): Human hallucinogen research: guidelines for safety. J Psychopharmacol 22:603-620.

47. Gouzoulis-Mayfrank E, Schneider F, Friedrich J, Spitzer M, Thelen B, Sass H (1998): Methodological issues of human experimental research with hallucinogens. Pharmacopsychiatry 31 Suppl 2:114-118.

48. Dittrich A (1998): The standardized psychometric assessment of altered states of consciousness (ASCs) in humans. Pharmacopsychiatry 31 Suppl 2:80-84.

49. Farre M, Abanades S, Roset PN, Peiro AM, Torrens M, O'Mathuna B, et al. (2007): Pharmacological interaction between 3,4-methylenedioxymethamphetamine (ecstasy) and paroxetine: pharmacological effects and pharmacokinetics. $J$ Pharmacol Exp Ther 323:954-962.

50. Janke W, Debus G (1978): Die Eigenschaftswörterliste. Göttingen: Hogrefe.

51. Hysek CM, Schmid Y, Simmler LD, Domes G, Heinrichs M, Eisenegger C, et al. (2013): MDMA enhances emotional empathy and prosocial behavior. Soc Cogn Affect Neurosci (in press).

52. Abraham HD, Aldridge AM, Gogia P (1996): The psychopharmacology of hallucinogens. Neuropsychopharmacology 14:285-298. 
53. Vollenweider FX, Vollenweider-Scherpenhuyzen MF, Babler A, Vogel H, Hell D (1998): Psilocybin induces schizophrenia-like psychosis in humans via a serotonin-2 agonist action. Neuroreport 9:3897-3902.

54. Hasler F, Grimberg U, Benz MA, Huber T, Vollenweider FX (2004): Acute psychological and physiological effects of psilocybin in healthy humans: a double-blind, placebo-controlled dose-effect study. Psychopharmacology 172:145-156.

55. Shulgin AT (1973): Mescaline: the chemistry and pharmacology of its analogs. Lloydia $36: 46-58$.

56. Vollenweider FX, Kometer M (2010): The neurobiology of psychedelic drugs: implications for the treatment of mood disorders. Nat Rev Neurosci 11:642-651.

57. Hysek CM, Domes G, Liechti ME (2012): MDMA enhances "mind reading" of positive emotions and impairs "mind reading" of negative emotions. Psychopharmacology (Berl) 222:293-302.

58. Griffiths RR, Richards WA, McCann U, Jesse R (2006): Psilocybin can occasion mystical-type experiences having substantial and sustained personal meaning and spiritual significance. Psychopharmacology (Berl) 187:268-283.

59. Schmid Y, Hysek CM, Simmler LD, Crockett MJ, Quednow BB, Liechti ME (2014): Differential effects of MDMA and methylphenidate on social cognition. $J$ Psychopharmacol 28:847-856.

60. Ramos L, Hicks C, Kevin R, Caminer A, Narlawar R, Kassiou M, et al. (2013): Acute prosocial effects of oxytocin and vasopressin when given alone or in combination with 3,4-methylenedioxymethamphetamine in rats: involvement of the $V_{1 \mathrm{~A}}$ receptor. Neuropsychopharmacology 38:2249-2259.

61. Liechti ME, Saur MR, Gamma A, Hell D, Vollenweider FX (2000): Psychological and physiological effects of MDMA ("Ecstasy") after pretreatment with the $5-\mathrm{HT}_{2}$ antagonist ketanserin in healthy humans. Neuropsychopharmacology 23:396-404. 
62. Titeler M, Lyon RA, Glennon RA (1988): Radioligand binding evidence implicates the brain 5- $\mathrm{HT}_{2}$ receptor as a site of action for LSD and phenylisopropylamine hallucinogens. Psychopharmacology (Berl) 94:213-216.

63. Hysek CM, Simmler LD, Nicola V, Vischer N, Donzelli M, Krähenbühl S, et al. (2012): Duloxetine inhibits effects of MDMA ("ecstasy") in vitro and in humans in a randomized placebo-controlled laboratory study. PLoS One 7:e36476.

64. Liechti ME, Gamma A, Vollenweider FX (2001): Gender differences in the subjective effects of MDMA. Psychopharmacology (Berl) 154:161-168.

65. Studerus E, Gamma A, Kometer M, Vollenweider FX (2012): Prediction of psilocybin response in healthy volunteers. PLoS One 7:e30800.

66. Braff DL, Geyer MA (1980): Acute and chronic LSD effects on rat startle: data supporting an LSD rat model of schizophrenia. Biol Psychiatry 15:909-916.

67. Vollenweider FX, Csomor PA, Knappe B, Geyer MA, Quednow BB (2007): The effects of the preferential 5-HT2A agonist psilocybin on prepulse inhibition of startle in healthy human volunteers depend on interstimulus interval. Neuropsychopharmacology 32:1876-1887.

68. Gouzoulis-Mayfrank E, Heekeren K, Thelen B, Lindenblatt $\mathrm{H}$, Kovar KA, Sass $\mathrm{H}$, et al. (1998): Effects of the hallucinogen psilocybin on habituation and prepulse inhibition of the startle reflex in humans. Behav Pharmacol 9:561-566.

69. Quednow BB, Kometer M, Geyer MA, Vollenweider FX (2012): Psilocybin-induced deficits in automatic and controlled inhibition are attenuated by ketanserin in healthy human volunteers. Neuropsychopharmacology 37:630-640.

70. Heekeren K, Neukirch A, Daumann J, Stoll M, Obradovic M, Kovar KA, et al. (2007): Prepulse inhibition of the startle reflex and its attentional modulation in the human Sketamine and N,N-dimethyltryptamine (DMT) models of psychosis. J Psychopharmacol 21:312-320. 
71. Gonzalez-Maeso J, Ang RL, Yuen T, Chan P, Weisstaub NV, Lopez-Gimenez JF, et al. (2008): Identification of a serotonin/glutamate receptor complex implicated in psychosis. Nature 452:93-97.

72. Quednow BB, Schmechtig A, Ettinger U, Petrovsky N, Collier DA, Vollenweider FX, et al. (2009): Sensorimotor gating depends on polymorphisms of the serotonin-2A receptor and catechol-O-methyltransferase, but not on neuregulin-1 Arg38Gln genotype: a replication study. Biol Psychiatry 66:614-620.

73. Kornetsky C (1957): Relation of physiological and psychological effects of lysergic acid diethylamide. AMA Arch Neurol Psychiatry 77:657-658.

74. Dimascio A, Greenblatt M, Hyde RW (1957): A study of the effects of L.S.D.: physiologic and psychological changes and their interrelations. Am J Psychiatry 114:309-317.

75. Sokoloff L, Perlin S, Kornetsky C, Kety SS (1957): The Effects of D-Lysergic Acid Diethylamide on Cerebral Circulation and over-All Metabolism. Annals of the New York Academy of Sciences 66:468-477.

76. Belleville RE, Fraser HF, Isbell H, Wikler A, Logan CR (1956): Studies on lysergic acid diethylamide (LSD-25): I. Effects in former morphine addicts and development of tolerance during chronic intoxication. AMA Arch Neurol Psychiatry 76:468-478.

77. Forrer GR, Goldner RD (1951): Experimental physiological studies with lysergic acid diethylamide (LSD-25). AMA Arch Neurol Psychiatry 65:581-588.

78. Hysek CM, Simmler LD, Ineichen M, Grouzmann E, Hoener MC, Brenneisen R, et al. (2011): The norepinephrine transporter inhibitor reboxetine reduces stimulant effects of MDMA ("ecstasy") in humans. Clin Pharmacol Ther 90:246-255.

79. Horita A, Dille JM (1954): Pyretogenic effect of Iysergic acid diethylamide. Science 120:1100-1101.

80. Klock JC, Boerner U, Becker CE (1975): Coma, hyperthermia, and bleeding associated with massive LSD overdose, a report of eight cases. Clin Toxicol 8:191-203. 
81. Isbell H (1959): Comparison of the reactions induced by psilocybin and LSD-25 in man. Psychopharmacologia 1:29-38.

82. Gouzoulis-Mayfrank E, Thelen B, Habermeyer E, Kunert HJ, Kovar KA, Lindenblatt H, et al. (1999): Psychopathological, neuroendocrine and autonomic effects of 3,4methylenedioxyethylamphetamine (MDE), psilocybin and d-methamphetamine in healthy volunteers: results of an experimental double blind placebo controlled study. Psychopharmacology 142:41-50.

83. Strassman RJ, Qualls CR (1994): Dose-response study of N,N-dimethyltryptamine in humans. I. Neuroendocrine, autonomic, and cardiovascular effects. Arch Gen Psychiatry 51:85-97.

84. Watts VJ, Lawler CP, Fox DR, Neve KA, Nichols DE, Mailman RB (1995): LSD and structural analogs: pharmacological evaluation at $D_{1}$ dopamine receptors. Psychopharmacology (Berl) 118:401-409.

85. Giacomelli S, Palmery M, Romanelli L, Cheng CY, Silvestrini B (1998): Lysergic acid diethylamide (LSD) is a partial agonist of $D_{2}$ dopaminergic receptors and it potentiates dopamine-mediated prolactin secretion in lactotrophs in vitro. Life Sci 63:215-222.

86. Meltzer HY, Fessler RG, Simonovic M, Doherty J, Fang VS (1977): Lysergic acid diethylamide: evidence for stimulation of pituitary dopamine receptors. Psychopharmacology (Berl) 54:39-44.

87. Sommers DK, van Wyk M, Snyman JR (1994): Dexfenfluramine-induced prolactin release as an index of central synaptosomal 5-hydroxytryptamine during treatment with fluoxetine. Eur J Clin Pharmacol 46:441-444.

88. Seifritz E, Baumann P, Muller MJ, Annen O, Amey M, Hemmeter U, et al. (1996): Neuroendocrine effects of a $20-\mathrm{mg}$ citalopram infusion in healthy males. a placebocontrolled evaluation of citalopram as 5-HT function probe. Neuropsychopharmacology 14:253-263. 
89. Callaway JC, McKenna DJ, Grob CS, Brito GS, Raymon LP, Poland RE, et al. (1999): Pharmacokinetics of Hoasca alkaloids in healthy humans. J Ethnopharmacol 65:243256.

90. Seibert J, Hysek CM, Penno CA, Schmid Y, Kratschmar DV, Liechti ME, et al. (2014): Acute effects of 3,4-methylenedioxymethamphetamine and methylphenidate on circulating steroid levels in healthy subjects. Neuroendocrinology (in press). 


\section{FIGURE LEGENDS}

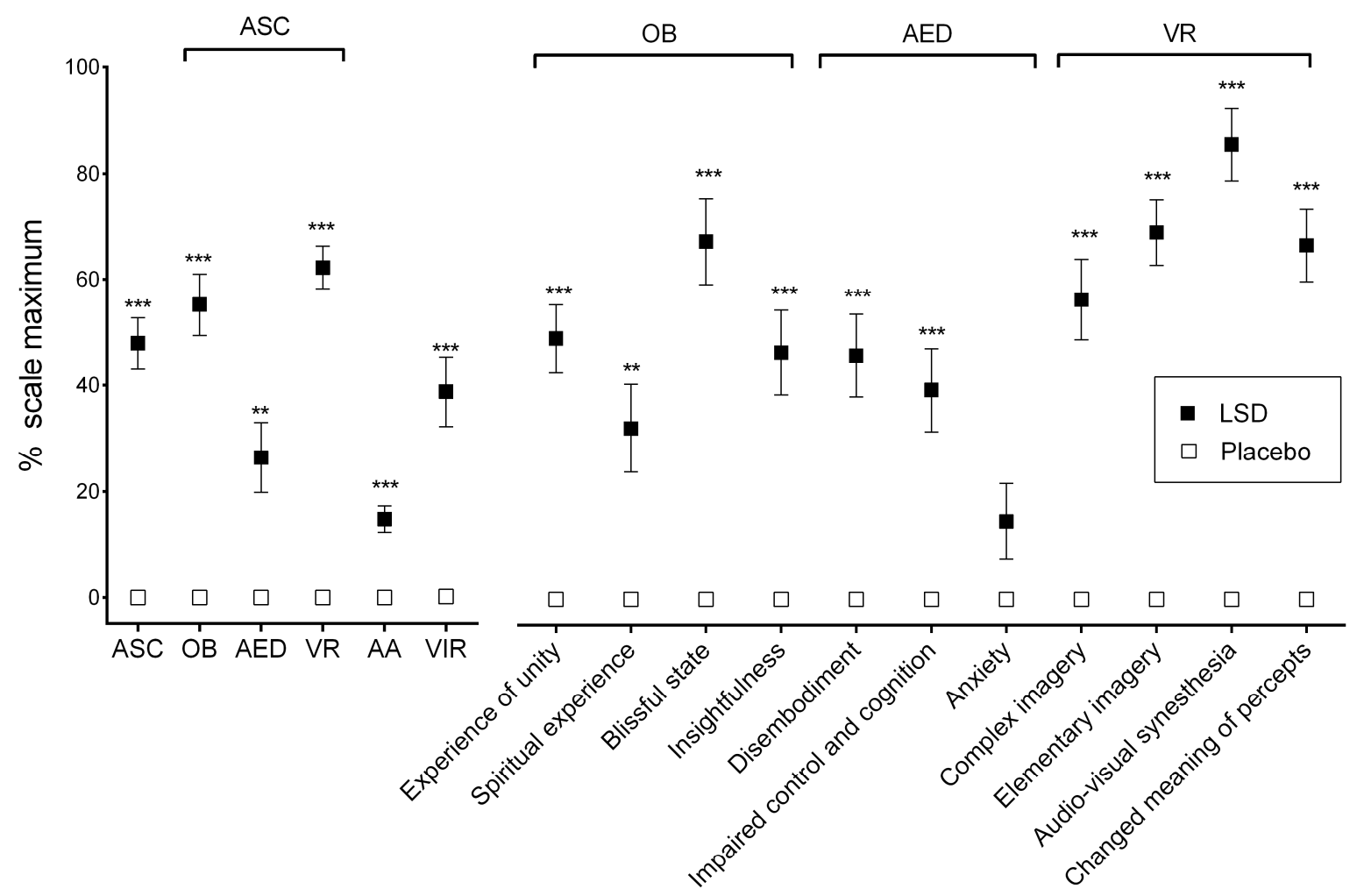

Figure 1. Effects of LSD on the Altered States of Consciousness (5D-ASC) scale. LSD predominantly increased ratings of oceanic boundlessness (OB) and visionary restructuralization (VR). Increased $\mathrm{OB}$ ratings mostly resulted from higher ratings for blissful state and experience of unity. Increases in VR ratings were attributable to high ratings for audio-visual synesthesia, elementary and complex imagery, and changed meaning of percepts. LSD produced only very little auditory alterations (AA). LSD-induced increases in anxious ego-dissolution (AED) were small because of elevated ratings for disembodiment, impaired control, and cognition but not anxiety. Vigilance (VIR) was significantly reduced by LSD compared with placebo. The global ASC score consists of the summation of the OB, AED, and VR scores. ${ }^{* *} p<.01,{ }^{* *} p<.001$, compared with placebo. The data are expressed as the mean \pm SEM in 16 subjects. 

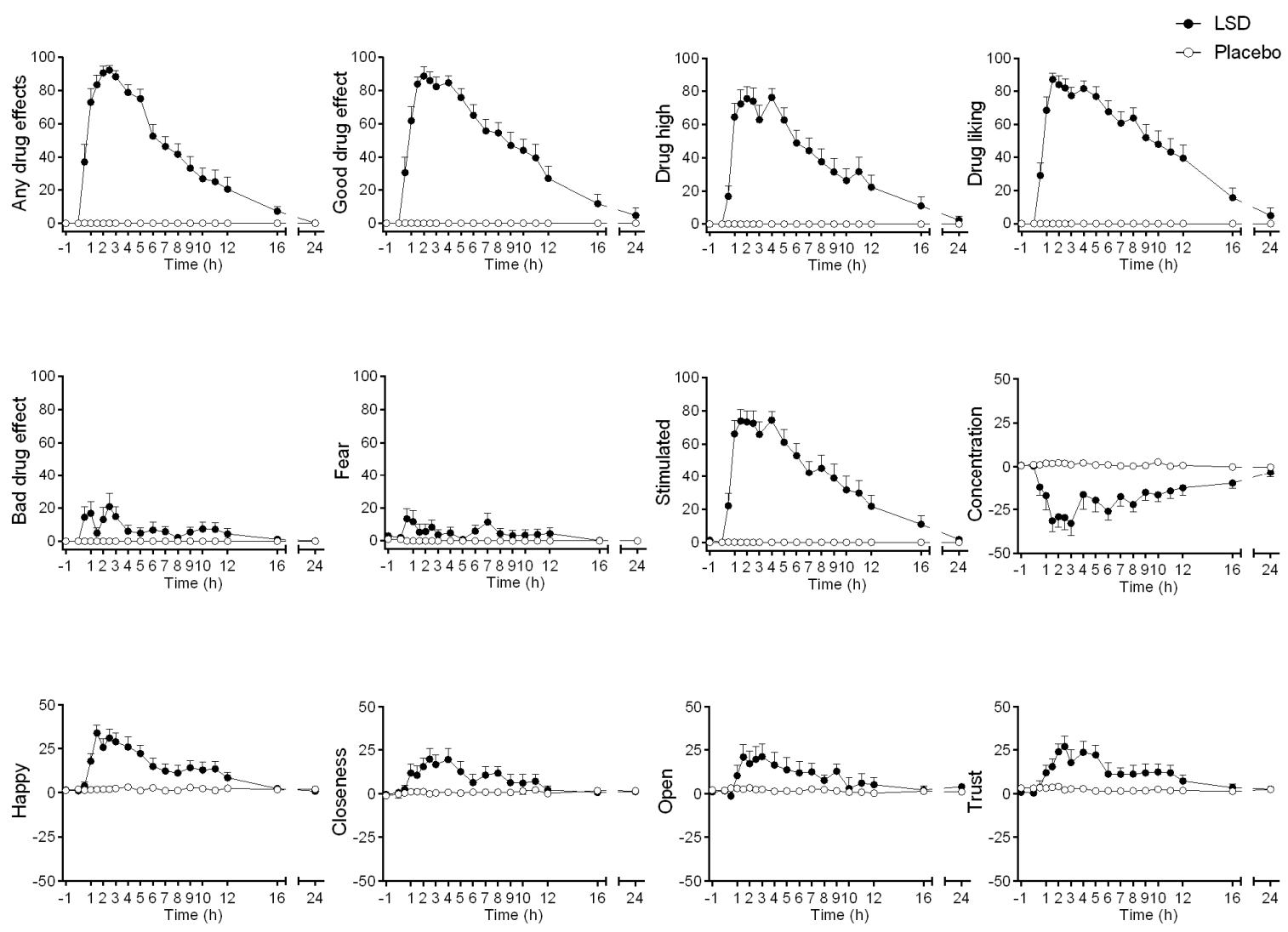

Figure 2. Subjective effects of LSD over time on the Visual Analogue Scales (VASs). LSD or placebo was administered at $t=0$. The subjective effects began $30-60$ min after LSD administration, peaked after $1-5 \mathrm{~h}$, gradually subsided after $5 \mathrm{~h}$, and were increased up to $12 \mathrm{~h}$. LSD produced significant changes in all VAS ratings. However, "bad drug effects" and "fear" were only minimally elevated. LSD also increased ratings that are typically increased by empathogens, including ratings for "happy," "closeness," "open," and "trust." The data are expressed as the mean \pm SEM \% maximal values in 16 subjects. 
A

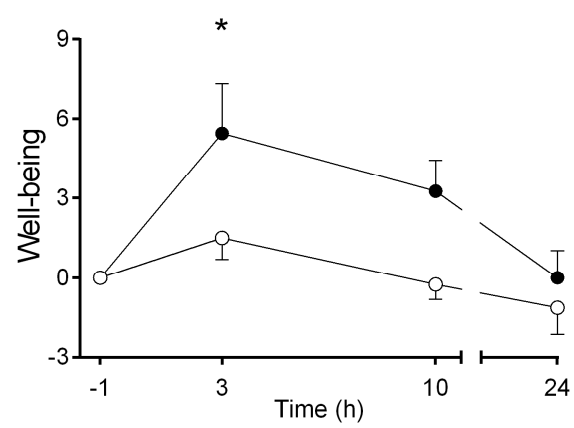

B

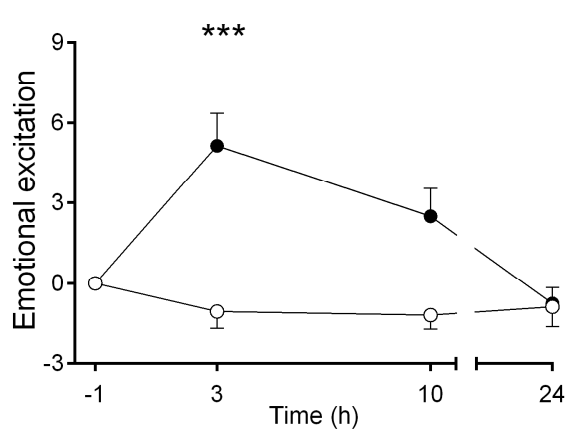

LSD

C

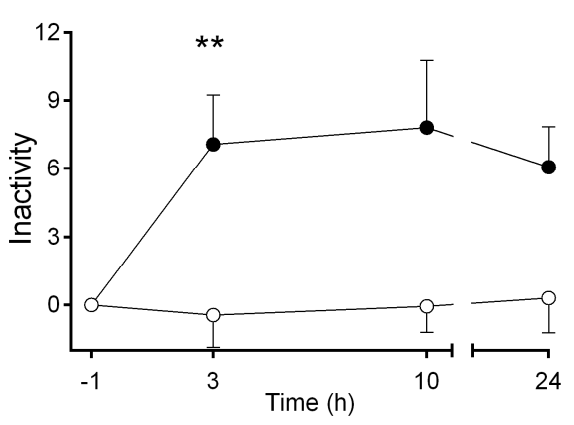

$\mathbf{F}$

E

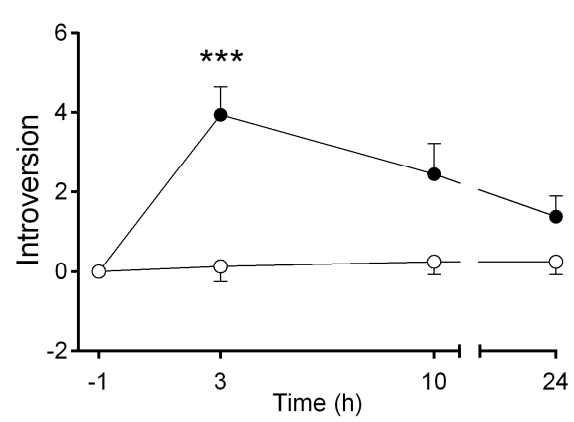

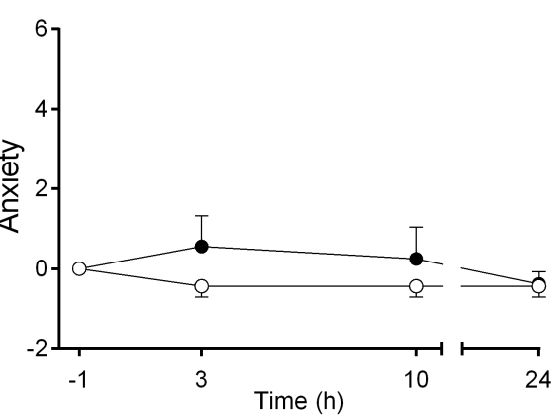

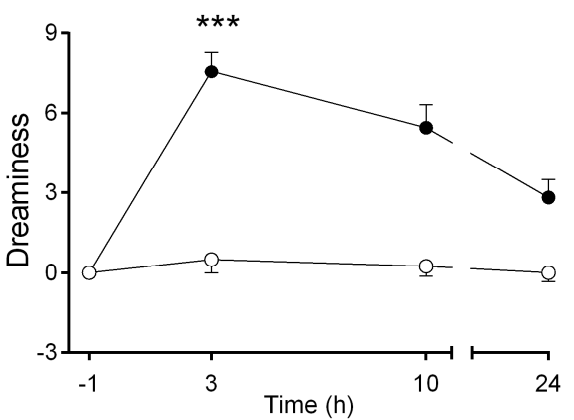

Figure 3. Subjective effects on the Adjective Mood Rating Scale (AMRS). LSD or placebo was administered at $t=0$. LSD induced increases in general well-being $(A)$, emotional excitation (B), inactivity (C), introversion (D), and dreaminess (F). LSD did not induce significant anxiety $(E)$. The data are expressed as the mean \pm SEM change from baseline in 16 subjects. ${ }^{*} p<.05,{ }^{* *} p<.01,{ }^{* *} p<.001$, compared with placebo. 
A

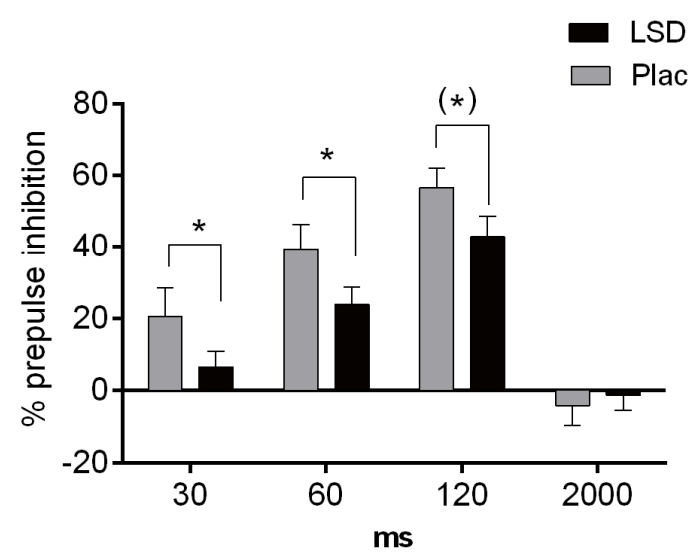

B

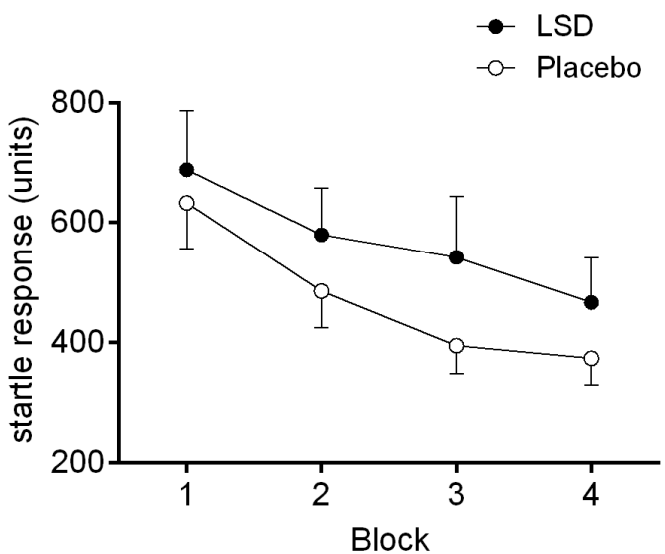

Figure 4. Effects of LSD on the percentage of prepulse inhibition (\%PPI) of the acoustic startle response $(A)$ and startle response habituation over time (B). LSD significantly reduced \%PPI in trials with prepulses that were presented 30 or $60 \mathrm{~ms}$ before the startle pulse compared with placebo (A). A trend toward a significant reduction of \%PPI was observed for the $120 \mathrm{~ms}$ prepulse trial condition. LSD did not significantly alter the startle response or startle response habituation compared with placebo $(B)$. The data are expressed as the mean \pm SEM in 15 subjects. ${ }^{*} p<.05,{ }^{(*)} p=.09$, compared with placebo. 
A
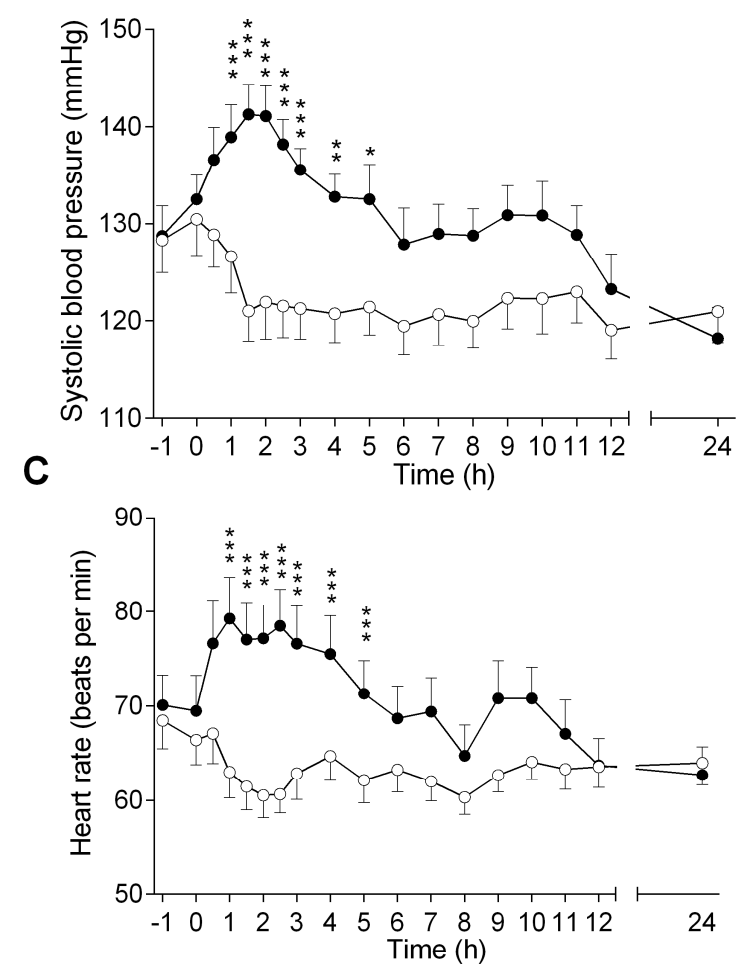

B

- LSD

-a Placebo
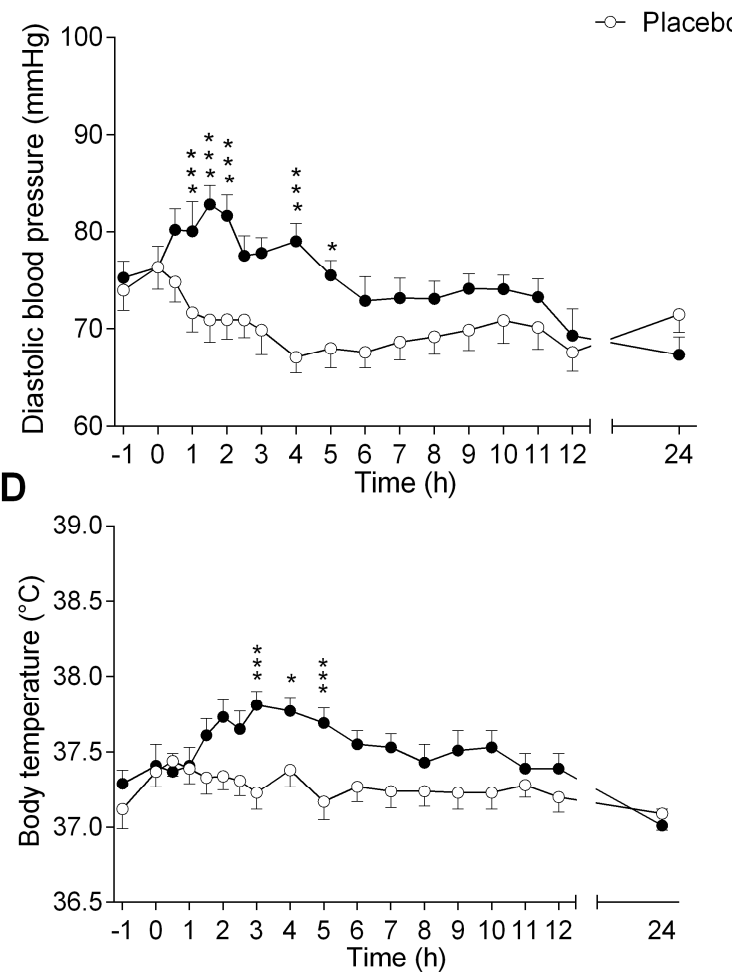

Figure 5. Effect of LSD on vital signs. LSD or placebo was administered at $t=0 \mathrm{~h}$. LSD significantly increased systolic (A) and diastolic (B) blood pressure, heart rate (C), and body temperature (D) compared with placebo. Comparisons for each time point revealed that the cardiostimulant $(A, B)$ and thermogenic $(D)$ changes induced by LSD were significant up to $5 \mathrm{~h}$ after drug administration compared with placebo, but moderate trend changes remained up to $11 \mathrm{~h}$ before the levels returned to baseline. The data are expressed as the mean \pm SEM in 16 subjects. ${ }^{*} p<.05,{ }^{* *} p<0.01,{ }^{* * *} p<.001$, compared with placebo. 

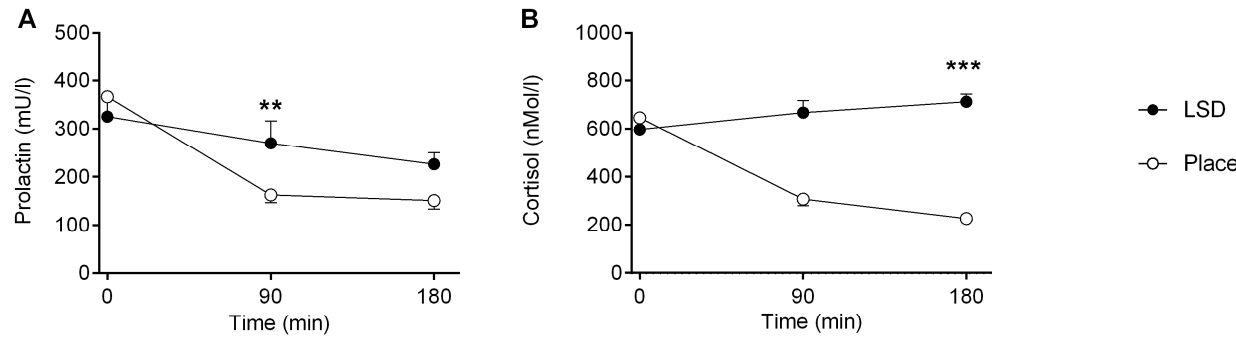

-o- Placebo

C

D

E
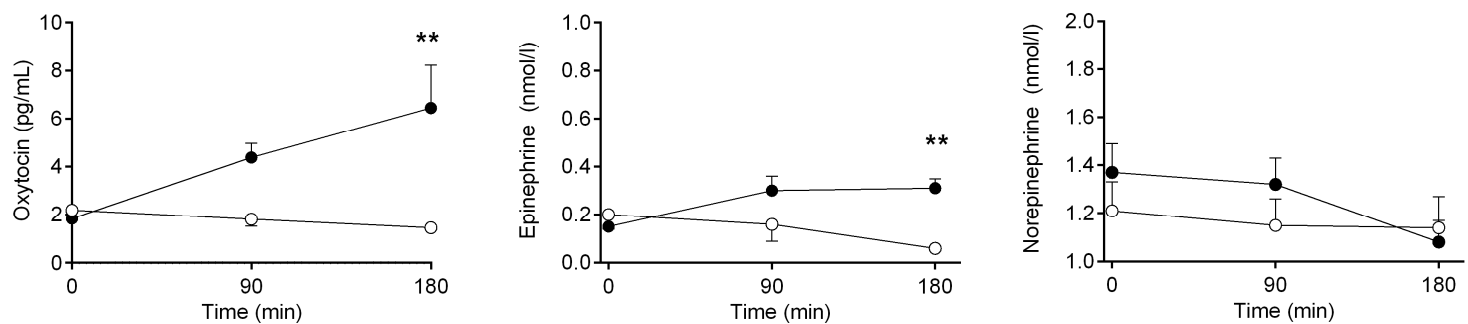

Figure 6. Endocrine effects of LSD. LSD significantly increased the plasma concentrations of prolactin $(A)$, cortisol $(B)$, oxytocin (C), and epinephrine (D). LSD did not significantly alter the plasma levels of norepinephrine (E). LSD or placebo was administered at $t=0 \mathrm{~min}$. The data are expressed as the mean \pm SEM in 16 subjects. ${ }^{* *} p<.01,{ }^{* *} p<.001$, compared with placebo. 